\title{
A Case-crossover Analysis of Air Pollution and Daily Mortality in Shanghai
}

\author{
Haidong KAN and Bingheng CHEN \\ Department of Environmental Health, School of Public Health, Fudan University, P.R. China
}

\begin{abstract}
A Case-crossover Analysis of Air Pollution and Daily Mortality in Shanghai: Haidong KAN, et al. Department of Environmental Health, School of Public Health, Fudan University, P. R. China-We used a case-crossover approach to assess the association between air pollution and daily mortality in Shanghai from June 2000 to December 2001. By design, this method can avoid some common concerns about the time-series approach, which was most frequently used to assess the short-term effects of air pollution. Different control periods (unidirectional and bi-directional control samplings) were used for the analysis. With a bi-directional six control sampling approach, the results from a conditional logistic regression model controlling for weather conditions showed that each $10 \mu \mathrm{g} / \mathrm{m}^{3}$ increase over a 48-h moving average of $\mathrm{PM}_{10}, \mathrm{SO}_{2}$ and $\mathrm{NO}_{2}$ corresponds to 1.003 (95\% Cl 1.001-1.005), 1.016 (95\%Cl $1.011-$ $1.021)$, and $1.020(95 \% \mathrm{Cl} 1.012-1.027)$ relative risk of non-accident mortality, respectively. The association between air pollution and mortality for chronic obstructive pulmonary diseases (COPD) and cardiovascular causes was found to be closer than that for all causes. The results confirmed the deleterious role of the current air pollution level on human health in Shanghai, and provided information on the applicability of case-crossover design in studying the acute health effects of air pollution.
\end{abstract}

(J Occup Health 2003; 45: 119-124)

Key words: Air pollution, Case-crossover, Mortality

Numerous studies have confirmed the association between air pollution and daily mortality outcomes ${ }^{1)}$. Most of these studies used contemporary time-series statistical analysis techniques to evaluate the health effects of acute or short-term exposure to air pollution. By design, time-series studies examine the same population

Received Oct 5, 2002; Accepted Feb 15, 2003

Correspondence to: H. KAN, Department of Environmental Health, School of Public Health, Fudan University, Shanghai 200032, P.R. China repeatedly under various exposure conditions, so that time-invariant characteristics, such as age and cigarette smoking, are no longer a potential confounder. This is a key advantage in the time-series approach. Recently, sophisticated analytical techniques, e.g. generalized additive models (GAM), have been introduced into the time-series studies for the adjustment of long-term and seasonal trends, weather variables, etc ${ }^{2)}$.

Nevertheless, some scientists have argued that the results of time-series studies are model dependent. The association between air pollution and adverse health outcomes in the time-series approach is sensitive to the selection of degree freedom (df) or window length in the gam model ${ }^{3)}$. Schwartz et al. suggested a potential bias in over-filtering certain patterns of exposure, which should be assessed if cumulative exposure effects are present ${ }^{4)}$. In addition, time-series studies lack a full enumeration and characterization of the population at risk.

The case-crossover design, which was firstly proposed by Maclure to study the transient effect of an intermittent exposure ${ }^{5}$, has been used to study the short-term effects of air pollution ${ }^{6-8)}$. The case-crossover approach is a design in which only cases are sampled, and their exposure at the time of their failure is compared with some estimate of their typical level of exposure. This approach only requires exposure data for cases and can be regarded as a special type of case-control study in which the case serves his/her referent. Therefore, the case-crossover design has the advantage of controlling for potential confounding caused by fixed individual characteristics, such as sex, race, diet and age. The bidirectional case-crossover design proposed by Navidi is able to control for time trends in the data through the use of information on the study subjects both before and after the event ${ }^{9}$. Also, due to the relatively short interval of time between the case and control periods, the casecrossover design could prevent many time-varying confounders.

In the present study, we used the case-crossover technique to evaluate the relationship between air 
pollution and daily mortality from June 2000 to December 2001 in Shanghai, and we also compared the results of the bi-directional control sampling approach with the unidirectional approach. The objective of this study is to estimate the effect of ambient air pollution on mortality, and to explore the applicability of case-crossover design in studying the acute health effects of air pollution.

\section{Materials and Methods}

\section{Data}

Data from June 1, 2000 to December 31, 2001 were collected. Daily death counts during the period for all non-accidental causes [International Classification of Diseases, Revision 9 (ICD-9) < 800], cardiovascular diseases (ICD-9 390-459), and chronic obstructive pulmonary diseases (COPD) (ICD-9 490-496) in the urban areas of Shanghai, which cover nine Administrative Districts and roughly $289 \mathrm{~km}^{2}$, were extracted from the database of Shanghai Center of Disease Control and Prevention. The data on Shanghai death certificates should be considered reliable because all data were reported by physicians, not by the relatives of the deceased. All mortality data and their accuracy were rechecked before entering into the database. Meteorologic data (daily average temperature, relative humidity and dew point), which were measured by one station in central Shanghai, were provided by Shanghai Meteorological Bureau. Air pollution data (daily average $\mathrm{PM}_{10}, \mathrm{SO}_{2}$ and $\mathrm{NO}_{2}$ concentrations) were retrieved from the database of Shanghai Environmental Monitoring Center. The air pollutant concentrations were averaged from the results monitored by six fix-site stations in the urban areas of Shanghai. According to Shanghai Environmental Monitoring Center, the six sites are scattered in different functional areas of Shanghai and their monitoring results could represent the average air pollution level in Shanghai. There were no missing data in the variables described above.

\section{Statistical methods}

Data analysis in case-crossover studies can be done by standard case-control methods. As originally formulated, exposures close in time to the event (case period) are contrasted with exposure at a typical time when an event did not occur (control period). In the present study, each death was considered as a stratum, and the death time and other times were defined as the matched case and control period, respectively. The association between mortality risk and air pollution was measured with the odds ratio in conditional logistic regression by means of the STATA statistical package (StataCorp, College Station, Texas). After control for the 48 -h mean temperature, the $24-\mathrm{h}$ mean relative humidity and dew point, odds ratios were expressed for each $10 \mu \mathrm{g} / \mathrm{m}^{3}$ increase in the air pollutants concentration.
We fitted models with a different combination of pollutants (up to three pollutants per model) to assess the stability of individual effects.

A number of control selection methosds have been proposed for the case-crossover design in air pollution studies. A detailed discussion of control sampling strategies for case-crossover studies has been previously published $^{10-12)}$. For our study, we used both unidirectional retrospective control samplings and bi-directional control samplings. In the unidirectional retrospective control samplings, the same weekdays 1, 2 or 3 wk before death were selected as the control periods; but for bi-directional control samplings, the same weekdays 1,2 or 3 wk before and after death were defined as the control periods. We chose the same weekdays as the control periods in order to avoid the day-of-the-week effect of mortality response. In addition, we also considered the lag effect of air pollutant concentrations on mortality and tested its effect up to a five-day lag in building the models.

\section{Results}

Description of daily mortality, air pollutant concentrations, and meteorologic measures

Summary statistics of mortality counts, air pollutant concentrations, and meteorologic measures are shown in Table 1. A total of 64,862 deaths were included in the analysis. During the period, on average there were 112 deaths per day in the total population in the study area, and approximately 39 persons died from cardiovascular diseases, and 11 persons from COPD.

Table 2 shows the correlation for daily values over the entire period among the air pollutants and weather variables. $\mathrm{PM}_{10}, \mathrm{SO}_{2}$ and $\mathrm{NO}_{2}$ had a strong positive correlation with one another and were negatively correlated with temperature, relative humidity and dew point.

\section{Case-crossover regression results}

The 48-h moving averages (including the concurrent day in which death occurred) of $\mathrm{PM}_{10}, \mathrm{SO}_{2}$ and $\mathrm{NO}_{2}$ levels resulted in the highest relationship to daily mortality. Therefore, we used the 48 -h average air pollutants concentrations for the regression model.

Odds ratios (ORs) varied for different control schemes (Table 3). Using six reference periods $(7,14$ and $21 \mathrm{~d}$ before and after the case period), a $10 \mu \mathrm{g} / \mathrm{m}^{3}$ increase in the 48-h averages of $\mathrm{PM}_{10}, \mathrm{SO}_{2}$ and $\mathrm{NO}_{2}$ were associated with the total mortality [odds ratio $(\mathrm{OR})=1.003(95 \% \mathrm{CI}$ 1.001-1.005), 1.016 (95\%CI 1.011-1.021), and 1.020 (95\%CI 1.012-1.027) respectively] after adjustment for 48-h mean temperature, 24-h mean relative humidity and dew point. A model with four symmetric reference periods 7 and $14 \mathrm{~d}$ around the case period produced a similar but weaker result. When only prior reference periods were used in the analysis, a larger effect was seen 
Table 1. Descriptive statistics of mortality outcomes, air pollution levels, and meteorologic measures in Shanghai $(\mathrm{n}=579)$

\begin{tabular}{lrrrrrrr}
\hline & Mean & SD & $10 \%$ & $25 \%$ & $50 \%$ & $75 \%$ & $90 \%$ \\
\hline Mortality Counts & & & & & & & \\
$\quad$ Non-accident & 112.02 & 21.08 & 88 & 96 & 108 & 126 & 143 \\
$\quad$ Cardiovascular diseases & 39.09 & 9.97 & 28 & 32 & 37 & 46 & 54 \\
$\quad$ COPD & 10.71 & 5.19 & 5 & 7 & 10 & 14 & 18 \\
Meteorologic measures & & & & & & & \\
$\quad$ Temperature $\left({ }^{\circ} \mathrm{C}\right)$ & 19.01 & 8.4 & 7.6 & 11.5 & 20.8 & 25.7 & 29.5 \\
$\quad$ Relative humidity $(\%)$ & 74.87 & 10.4 & 62.0 & 68.0 & 75.5 & 81.5 & 88.8 \\
$\quad$ Dew Point $\left({ }^{\circ} \mathrm{C}\right)$ & 14.14 & 8.9 & 2.1 & 6.8 & 15.6 & 21.7 & 24.8 \\
Air pollutants concentrations & & & & & & & \\
$\quad \mathrm{PM}_{10}\left(\mu \mathrm{g} / \mathrm{m}^{3}\right)$ & 91.14 & 51.85 & 43 & 54 & 76 & 114 & 163 \\
$\mathrm{SO}_{2}\left(\mu \mathrm{g} / \mathrm{m}^{3}\right)$ & 42.49 & 20.17 & 20 & 28 & 39 & 52 & 68 \\
$\mathrm{NO}_{2}\left(\mu \mathrm{g} / \mathrm{m}^{3}\right)$ & 32.46 & 14.43 & 18 & 23 & 30 & 37 & 54 \\
\hline
\end{tabular}

Table 2. Pearson correlation coefficients among daily weather and air pollution variables in Shanghai from June 2000 to Dec 2001

\begin{tabular}{lrrrrrr}
\hline & $\mathrm{PM}_{10}$ & $\mathrm{SO}_{2}$ & $\mathrm{NO}_{2}$ & Temperature & Relative humidity & Dew point \\
\hline $\mathrm{PM}_{10}$ & 1.00 & & & & & \\
$\mathrm{SO}_{2}$ & 0.71 & 1.00 & & & & \\
$\mathrm{NO}_{2}$ & 0.73 & 0.75 & 1.00 & & & \\
Temperature & -0.29 & -0.25 & -0.39 & 1.00 & & \\
Relative humidity & -0.36 & -0.47 & -0.17 & 0.21 & 1.00 & 1.00 \\
Dew point & -0.36 & -0.36 & -0.41 & 0.97 & 0.45 & \\
\hline
\end{tabular}

Table 3. Odds ratios and $95 \%$ confidence intervals (CI) of the association of daily total mortality with a $10 \mu \mathrm{g} / \mathrm{m}^{3}$ increase in the 48-h average of air pollutants in Shanghai in different control schemes

\begin{tabular}{ccccccccc}
\hline & \multicolumn{2}{c}{$\mathrm{PM}_{10}$} & & \multicolumn{2}{c}{$\mathrm{SO}_{2}$} & & \multicolumn{2}{c}{$\mathrm{NO}_{2}$} \\
\cline { 2 - 3 } & Mean & $95 \% \mathrm{CI}$ & & Mean & $95 \% \mathrm{CI}$ & & Mean & $95 \% \mathrm{CI}$ \\
\hline Before and after case period & & & & & & & & \\
$7 \mathrm{~d}$ & 1.000 & $0.998-1.002$ & & 1.004 & $0.999-1.009$ & & 1.000 & $0.992-1.008$ \\
7 and 14 d & 1.002 & $1.000-1.004$ & & 1.009 & $1.003-1.014$ & & 1.007 & $1.000-1.014$ \\
7,14 and 21 d & 1.003 & $1.001-1.005$ & & 1.016 & $1.011-1.021$ & & 1.020 & $1.012-1.027$ \\
\hline Before case period only & & & & & & & & \\
$7 \mathrm{~d}$ & 1.015 & $1.012-1.018$ & & 1.035 & $1.028-1.042$ & & 1.058 & $1.048-1.068$ \\
7 and 14 d & 1.017 & $1.015-1.019$ & & 1.034 & $1.027-1.039$ & & 1.062 & $1.053-1.071$ \\
7,14 and 21 d & 1.019 & $1.012-1.021$ & & 1.037 & $1.032-1.043$ & & 1.066 & $1.058-1.074$ \\
\hline
\end{tabular}

for each pollutant.

We also explored the effects of air pollutants levels on the changes in cause-specific mortality (Table 4). With six control samplings before and after the case period, the odds ratios for all-causes, cardiovascular disease and COPD mortality were found to be significantly associated with the increase in air pollution levels, among which
COPD mortality risk showed the closest association for every air pollutant studied.

Table 5 shows the comparison of the single-pollutant model and the multiple pollutants model. The effect of $\mathrm{PM}_{10}$ on total mortality was not significant after adjustment for $\mathrm{SO}_{2}$ or $\mathrm{NO}_{2}$ or both. For $\mathrm{SO}_{2}$, its effect on mortality was not affected by adding the other two 
Table 4. The odds ratios and $95 \%$ confidence intervals (CI) of the association of cause-specific mortality with a $10 \mu \mathrm{g} / \mathrm{m}^{3}$ increase in the 48 -h average of air pollutants in Shanghai*

\begin{tabular}{|c|c|c|c|c|c|c|}
\hline & \multicolumn{2}{|c|}{$\mathrm{PM}_{10}$} & \multicolumn{2}{|c|}{$\mathrm{SO}_{2}$} & \multicolumn{2}{|r|}{$\mathrm{NO}_{2}$} \\
\hline & Mean & $95 \% \mathrm{CI}$ & Mean & $95 \% \mathrm{CI}$ & Mean & $95 \% \mathrm{CI}$ \\
\hline All-causes & 1.003 & $1.001-1.005$ & 1.016 & $1.011-1.021$ & 1.020 & $1.012-1.027$ \\
\hline Cardiovascular diseases & 1.004 & $1.001-1.007$ & 1.017 & $1.009-1.026$ & 1.024 & $1.011-1.036$ \\
\hline COPD & 1.006 & $0.999-1.013$ & 1.033 & $1.017-1.049$ & 1.042 & $1.019-1.067$ \\
\hline
\end{tabular}

*: Six controls $(7,14,21 \mathrm{~d}$ before and after the case period) were matched;

Table 5. Relative risk of total mortality with a $10 \mu \mathrm{g} / \mathrm{m}^{3}$ increase in the $48-\mathrm{h}$ average of air pollutants in a single and multiple pollutant model*

\begin{tabular}{lcc}
\hline & mean & $95 \% \mathrm{CI}$ \\
\hline $\mathrm{PM}_{10}$ & 1.003 & $1.001-1.025$ \\
$\quad$ adjusted for $\mathrm{SO}_{2}$ & 0.997 & $0.994-1.025$ \\
adjusted for $\mathrm{NO}_{2}$ & 0.997 & $0.994-1.025$ \\
$\quad$ adjusted for both $\mathrm{SO}_{2}$ and $\mathrm{NO}_{2}$ & 0.995 & $0.992-1.025$ \\
\hline $\mathrm{SO}_{2}$ & 1.016 & $1.011-1.025$ \\
$\quad$ adjusted for $\mathrm{PM}_{10}$ & 1.022 & $1.015-1.025$ \\
adjusted for $\mathrm{NO}_{2}$ & 1.015 & $1.007-1.025$ \\
adjusted for both $\mathrm{PM}_{10}$ and $\mathrm{NO}_{2}$ & 1.018 & $1.009-1.025$ \\
\hline $\mathrm{NO}_{2}$ & 1.020 & $1.012-1.025$ \\
$\quad$ adjusted for $\mathrm{PM}_{10}$ & 1.028 & $1.017-1.025$ \\
adjusted for $\mathrm{SO}_{2}$ & 1.003 & $0.991-1.025$ \\
adjusted for both $\mathrm{PM}_{10}$ and $\mathrm{SO}_{2}$ & 1.012 & $0.998-1.025$ \\
\hline
\end{tabular}

*: Six controls (7, 14, $21 \mathrm{~d}$ before and after the case period) were matched;

pollutants. For $\mathrm{NO}_{2}$, including $\mathrm{PM}_{10}$ did not alter its effect; but when $\mathrm{SO}_{2}$ is added the $\mathrm{NO}_{2}$ effect becomes statistically insignificant. It is suggested that gas pollutants, especially $\mathrm{SO}_{2}$, may be a more important health-based exposure indicator than particulate matter in Shanghai.

\section{Discussion}

In an earlier time-series analysis of the same data, we found a significant association between the air pollutants $\left(\mathrm{PM}_{10}, \mathrm{SO}_{2}\right.$ and $\left.\mathrm{NO}_{2}\right)$ level and daily mortality in Shanghai. With the generalized additive model (GAM), an increase of $10 \mu \mathrm{g} / \mathrm{m}^{3}$ in $\mathrm{PM}_{10}, \mathrm{SO}_{2}$ and $\mathrm{NO}_{2}$ corresponds to 1.003 (95\% CI 1.001-1.005), 1.014 (95\%CI 1.008-1.020) and 1.015 (95\%CI 1.008-1.022) relative risk of non-accident mortality, respectively. Similar results were also obtained in this case-crossover study, but our study shows that the results of casecrossover studies greatly depend on the selection of control sampling methods. We could see from Table 3 that 4 and 6 controls before and after case periods provide similar results to the time-series study, and unidirectional retrospective control samplings produce an obviously larger effect. Just as Navidi pointed out, the results of unidirectional control sampling could be severely biased when time trends in exposure were strong, especially considering the relatively weak association between air pollution and health outcomes. To solve the problem, he described a bi-directional design for case-crossover analysis of exposure with time trends ${ }^{9}$.

Most of the previous studies on the relationship between air pollution and health outcomes have been based on the Poisson regression time-series approach. A case-crossover design offers the ability to control many confounders by design rather than by statistical modeling, thus offering the opportunity to improve causal inference of air pollution effects. Because each subject serves as his or her own control, invariant subject-specific covariables such as gender and age do not act as confounders. Also, by choosing the control period in multiples of $7 \mathrm{~d}$ and within a few weeks of death, this approach reduced any potential confounding role of the time trends, seasonality, and weather variables, but a disadvantage of case-crossover approach is that it is less 
precise than other statistical options such as the timeseries GAM approach. According to one simulation study, the ratio of the mean variance of GAM analyses to that of the case-crossover analyses with two controls was about $66 \%{ }^{13)}$. This reduction of efficiency is due largely to the loss of information from the control periods that cannot be included in the analysis ${ }^{14)}$. The efficiency can be increased by sampling more control periods, but there will often be a trade-off between precision of the estimates and bias that may be introduced ${ }^{10)}$. It is not clear that the case-crossover design is necessarily superior or inferior to the time-series approach, but the fact that the two different methods provided relatively similar results suggested that the association between air pollution and mortality was reasonably robust and probably not due to methodologic bias or confounders.

Our study also confirmed the previous findings that the association between air pollution and the mortality risks of cardiovascular diseases and COPD were stronger than all-cause mortality risk. Recently there have been many studies concerned with the potential mechanisms linking air pollution to cardiovascular and respiratory diseases. For example, air pollution has been associated with increased plasma viscosity ${ }^{15)}$, changes in the characteristics of the blood ${ }^{16)}$, anomaly indicators of autonomic function of the heart including increased heart rate, decreased heart rate variation, and increased cardiac arrhythmias ${ }^{17)}$. These findings provide possible pathways in which air pollution affects the cardiovascular system. For COPD, patients with such a disease often have a systemic deficit in their antioxidant defenses ${ }^{18)}$, and air pollution could have produced a significant additive oxidative stress ${ }^{19)}$ as a response to the inflammation of the lungs ${ }^{18)}$. An alternative explanation of the COPD susceptibility was that lung deposition of inhaled air pollutants was much higher in patients with obstructive airways diseases than in normal subjects ${ }^{20}$. Our study also showed that the association of air pollution with COPD mortality risk was closer than with cardiac death risk. This observation is consistent with our previous time-series analysis on the same data and those reported by Sunyer $\mathrm{J}$ et al in Barcelona ${ }^{7}$.

The limitations of our analyses should be noted. As in other ecological studies in this field, we used available environmental monitoring data to represent the population exposure to air pollutants. Measurement error may have substantial implications for interpreting epidemiologic studies on air pollution, particularly for the time-series and case-crossover analyses ${ }^{21)}$. It is possible that this type of error may introduce bias to our analysis results. This bias probably underestimated the association ${ }^{22)}$, but due to lack of available information on personal exposure, we could not quantify the bias. In addition, validity of the cause of death was limited, since we had access only to the death certificates so that misclassification of death causes is possible.

In reality, people cannot selectively inhale some air pollutants and not others. The results of the air pollutants correlation analysis also suggested that all of the pollutants might be indicators of the same pollutant mixture (see Table 2). Therefore, human health effects should be the result of a complex of inhaled pollutants, and it was very difficult to separate the effects of individual pollutants. For the present, the question whether there are independent effects of a single pollutant to account for a health outcome is still not settled. For example, in the United States, particulate matter is regarded as the pollutant that accounts for most excess mortality due to air pollution ${ }^{23)}$, but in Europe, several studies indicated a stronger association with sulfur dioxide $^{25)}$. Other studies showed that independent effects of individual pollutants can not be identified in light of the complexity and variability of the air pollution mixtures to which people are exposed ${ }^{24,25}$. Nevertheless, our study suggests that gas pollutants, especially $\mathrm{SO}_{2}$, are more closely associated death risk than particulate matter in Shanghai (see Table 5). Considering that the present air pollution epidemiologic studies use ambient pollutant concentrations as surrogates of personal exposure, we assumed that health effects attributed to the ambient gases, e.g. $\mathrm{SO}_{2}$ and $\mathrm{NO}_{2}$, may actually be a result of exposures to fine particles ${ }^{26,27)}$.

In summary, it seems clear that the current air pollution level in Shanghai was related to an increased daily mortality and that patients with COPD and cardiovascular disease were particularly susceptible. Our findings strengthen the evidence of the short-term effect of air pollution on mortality in China ${ }^{28,29)}$ and worldwide ${ }^{30)}$. This study also suggests that the case-crossover approach in principle is a useful tool in studying the association between premature death and air pollution, especially considering that the design could be carried out with any statistical software package supporting conditional logistic regression, whereas a generalized additive model could only be implemented in more advanced software, such as S-Plus, SAS etc.

\section{References}

1) DM Stieb, S Judek and RT Burnett: Meta-analysis of time-series studies of air pollution and mortality: effects of gases and particles and the influence of cause of death, age, and season. J Air Waste Manag Assoc 52, 470-484 (2002)

2) Hastie TJ, Tibshirani RJ. Generalized Additive Models. London: Chapman and Hall, 1990.

3) S Cakmak, R Burnett and D Krewski: Adjusting for temporal variation in analysis of parallel time series of health and environmental variables. J Expos Anal Environ Epidemiol 8, 129-144 (1997)

4) J Schwartz, C Spix, G Touloumi, L Bacharova, T Barumamdzadeh, A le Tertre, T Piekarksi, A Ponce de 
Leon, A Ponka, G Rossi, M Saez and JP Schouten: Methodological issues in studies of air pollution and daily counts of deaths or hospital admissions. J Epidemiol Comm Health 50, 3-11 (1996)

5) M Maclure: The case-crossover design: a method for studying transient effects on the risk of acute events. Am J Epidemi 133, 144-153 (1991)

6) D Levy, L Sheppard, H Checkoway, J Kaufman, T Lumley, J Koenig and D Siscovick: A case-crossover analysis of particulate matter air pollution and out-ofhospital primary cardiac arrest. Epidemiology 12, 193199 (2001)

7) J Sunyer, J Schwartz, A Tobias, D Macfarlane, J Garcia and JM Anto: Patients with chronic obstructive pulmonary disease are at increased risk of death associated with urban particle air pollution: a casecrossover analysis. Am J Epidemiol 151, 50-56 (2000)

8) W Navidi, D Thomas, B Langholz and D Stram: Statistical methods for epidemiologic studies of the health effects of air pollution. Res Rep Health Eff Inst 86, 1-50 (1999)

9) W Navidi: Bidirectional case-crossover designs for exposures with time trends. Biometrics 54, 596-605 (1998)

10) MA Mittleman, M Maclure and JM Robins: Control sampling strategies for case-crossover studies: an assessment of relative efficiency. Am J Epidemiol 142, 91-98 (1995)

11) D Levy, T Lumley, L Sheppard, J Kaufman and H Checkoway: Referent selection in case-crossover analyses of acute health effects of air pollution. Epidemiology 12, 186-192 (2001)

12) JT Lee, H Kim and J Schwartz: Bidirectional casecrossover studies of air pollution: bias from skewed and incomplete waves. Environ Health Perspect 108, 1107-1111 (2000)

13) TF Bateson and J Schwartz: Control for seasonal variation and time trend in case-crossover studies of acute effects of environmental exposures. Epidemiology 10, 539-544 (1999)

14) CA III Pope: Mortality and air pollution: associations persist with continued advances in research methodology. Environ Health Perspect 107, 613-614 (1999)

15) A Peters, A Döring, HE Wichmann and W Koenig: Increased plasma viscosity during an air pollution episode: a link to mortality? Lancet 349 , 1582-1587 (1997)

16) A Seaton, A Soutar, V Crawford, R Elton, S McNerlan, J Cherrie, M Watt, R Agius and R Stout: Particulate air pollution and the blood. Thorax 54, 1027-1032 (1999)

17) DW Dockery: Epidemiologic evidence of cardiovascular effects of particulate air pollution. Environ Health Perspect 109, 483-486 (2001)

18) I Rahman, D Morrison, K Donaldson and W MacNee:
Systemic oxidative stress in asthma, COPD, and smokers.Am J Respir Crit Care Med 154, 1055-1060 (1996)

19) XY Li, PS Gilmour, K Donaldson and W MacNee: Free radical activity and pro-inflammatory effects of particulate air pollution (PM10) in vivo and in vitro. Thorax 51, 1216-1222 (1996)

20) CS Kim adn TC Kang: Comparative measurement of lung deposition of inhaled fine particles in normal subjects and patients with obstructive airway disease. Am J Respir Crit Care Med 155, 899-905 (1997)

21) SL Zeger, D Thomas, F Dominici, JM Samet, J Schwartz, D Dockery and A Cohen: Exposure measurement error in time-series studies of air pollution: concepts and consequences. Environ Health Perspect 108, 419-426 (2000)

22) K Katsouyanni, G Touloumi, C Spix, J Schwartz, F Balducci, S Medina, G Rossi, B Wojtyniak, J Sunyer, L Bacharova, JP Schouten, A Ponka and HR Anderson: Short term effects of ambient sulphur dioxide and particulate matter on mortality in 12 European cities: results from time series data from the APHEA project. Air Pollution and Health: a European Approach. Br Med J 314, 1658-1663 (1997)

23) JM Samet, F Dominici, FC Curriero, I Coursac and SL Zeger: Fine particulate air pollution and mortality in 20 U.S. cities, 1987-1994. N Engl J Med 343, 17421749 (2000)

24) K Ito, GD Thurston, C Hayes and M Lippmann: Associations of London, England, daily mortality with particulate matters, sulphur dioxide and acidic aerosol pollution. Arch Environ Health 48, 213-220 (1993)

25) VH Borja-Aburto, DP Loomis, SI Bangdiwala, CM Shy and RA Rascon-Pacheco: Ozone, suspended particulates and daily mortality in Mexico City. Am J Epidemiol 145, 258-268 (1997)

26) J Schwartz, DW Dockery, LM Neas, D Wypij, JH Ware, JD Spengler, P Koutrakis, FE Speizer and BG Ferris: Acute effects of summer air pollution on respiratory symptom reporting in children. Am J Respir Crit Care Med 150, 1234-1242 (1994)

27) JA Sarnat, J Schwartz, PJ Catalano and HH Suh: Gaseous pollutants in particulate matter epidemiology: confounders or surrogates? Environ Health Perspect 109, 1053-1061 (2001)

28) $\mathrm{Z} \mathrm{Xu}, \mathrm{D} \mathrm{Yu}, \mathrm{L}$ Jing and $\mathrm{X} \mathrm{Xu}$ : Air pollution and daily mortality in Shenyang, China. Arch Environ Health $55,115-120$ (2000)

29) $\mathrm{X} \mathrm{Xu}, \mathrm{J}$ Gao, DW Dockery and Y Chen: Air pollution and daily mortality in residential areas of Beijing, China. Arch Environ Health 49, 216-222 (1994)

30) Committee of the Environmental and Occupational Health Assembly of the American Thoracic Society: Health effects of outdoor air pollution. Am J Respir Crit Care Med 153, 477-498 (1996) 